This is a peer-reviewed, accepted author manuscript of the following article: Javadi, Y., \& Najafabadi, M. A. (2013). Comparison between contact and immersion ultrasonic method to evaluate welding residual stresses of dissimilar joints. Materials and

\title{
Comparison between Contact and Immersion Ultrasonic Method to Evaluate Welding Residual Stresses of Dissimilar Joints
}

\author{
Yashar Javadi ${ }^{1}$ \\ ${ }^{1}$ Department of Mechanical Engineering, Islamic Azad University-Semnan Branch, Semnan, Iran. \\ (Corresponding author's e-mail: yasharejavadi@yahoo.com; Tel: +98 9124402303, Fax: +98 231335 4030.) \\ Mehdi Ahmadi Najafabadi ${ }^{2}$ \\ 2 Department of Mechanical Engineering, Amirkabir University of Technology, 424 Hafez Ave., Tehran, Iran. \\ ahmadin@aut.ac.ir
}

\begin{abstract}
This paper presents a comparison of contact and immersion waves used to measure residual stresses. The residual stresses are produced due to a dissimilar welding of stainless steel (304) to carbon steel (A106). Longitudinal critically refracted $\left(L_{C R}\right)$ wave propagated by $2 \mathrm{MHz}$ contact and immersion ultrasonic transducers is employed to measure the residual stresses. A finite element (FE) model of welding process, which is validated by hole-drilling method, is used to verify the ultrasonic results while an acceptable agreement is achieved. The best agreement is observed in the parent material while the maximum difference is measured in the heat affected zone (HAZ). The results show no considerable difference between using contact and immersion transducers in ultrasonic stress measurement of dissimilar joints.
\end{abstract}

Keywords: Finite Element Welding Simulation; Dissimilar Welding; Non-destructive Stress Measurement; Welding Residual Stress; Immersion Ultrasonic Method; Acoustoelastic Constant.

\section{Introduction}

The demand for fabrication of dissimilar joints is continuously increasing due to their advantages which can provide suitable mechanical properties along with cost reduction [1]. Dissimilar metal joints between pipes of ferritic and austenitic steels are extensively utilized in engineering structures such as steam generators of power plants. Austenitic stainless steel has a thermal conductivity of one third of carbon steel. The austenitic stainless steel have also a $50 \%$ greater thermal expansion than carbon steels which along with a lower thermal conductivity are prone to uneven expansion and distortion when they are joined together. Residual stresses of welded structures are produced as a result of non uniform thermal expansions and contractions during the welding processes. The residual stresses are measured by Olabi and Hashmi [2] where it has been shown that the post-weld heat-treatment lead to reducing residual stresses by about $70 \%$. The welding residual stresses are also measured by them in different studies [3-6] to investigate the influence of various parameters on the stresses of welded structures manufactured from low carbon steel and stainless steel. However, the residual stresses are severely complicated when subjected to differences in the coefficient of thermal expansion and thermal conductivity between the welded components [7]. Effect of laser welding conditions on toughness of dissimilar welded components is studied by Anawa and Olabi [8] where they applied the Taguchi technique on dissimilar welding process. They used the Taguchi approach as statistical design of experiment (DOE) technique for optimizing the welding parameters in terms of minimizing the fusion zone [1]. They also developed their statistical models to laser welding of the dissimilar joints [7] where the influence of the input parameters on the residual stress at different specimen levels is described to predict their value.

Non-destructive measurement of residual stress is important to optimize the structures' design and control their mechanical strength. One of the promising directions in the development of non-destructive techniques for residual stresses measurement 
is the application of ultrasound [9]. Stress measurement by the ultrasonic waves is a non-destructive, easy to use, and reasonably inexpensive method used in some industrial applications recently. Ultrasonic stress measurement is based on the linear relationship between the velocity of ultrasonic wave and the stress of material. This relationship, within the elastic limit, is the acoustoelastic effect which says that ultrasonic wave flight time varies with stress. The longitudinal critically refracted $\left(L_{C R}\right)$ wave is a longitudinal ultrasonic wave which can travel parallel to the surface. It is shown by Egle and Bray [10] that sensitivity of the $L_{C R}$ waves to the strain is highest among the other types of ultrasonic waves. Residual stress measurements in steel plates and welds using $L_{C R}$ waves was done by Leon-Salamanca and Bray [11]. They have investigated the effect of stress relieving on the ultrasonic waves. Tanala et al [12] determined acoustoelastic constant of 316L stainless steel and 5086 aluminium. The $L_{C R}$ measurements was done in immersion mode by Belahcene and Lu [13] to measure residual stress of S355 welded steel plate. They used hole-drilling method to verify the ultrasonic results. They also measured the penetration depth of $L_{C R}$ by using a gauge block with different groove depth. The results showed that the penetration depth of $L_{C R}$ wave was equivalent to one wavelength. Palanichamy et al [14] measured the residual stresses in austenitic stainless steel weld joints by using ultrasonic technique.

However, ultrasonic stress measurement of a dissimilar joint was investigated in none of the previous studies and pipe stresses are measured ultrasonically in a limited scale. Furthermore, $L_{C R}$ waves were usually employed in the contact mode while the immersion and contact method are simultaneously used in this study to evaluate residual stresses of dissimilar welded plate and pipe.

Welding simulation by Finite Element (FE) has become a popular method for the prediction of welding residual stresses and deformations. Earlier studies of welding simulation accounted for the nonlinearities because of temperature dependent material properties and plastic deformations [15]. Good agreements have been observed between the numerical predictions and experimental results [16-17] which encourage using FE welding simulation in residual stress evaluation. A finite element model, which is validated by hole-drilling method, is used here to verify the ultrasonic stress measurements.

\section{Theoretical Background}

\section{1. $L_{C R}$ Method}

The $L_{C R}$ method uses a special longitudinal bulk wave mode, as shown in Fig. 1, mainly propagating beneath the surface at a certain depth. When a longitudinal wave passes through an interface between two materials, there is an incident angle that makes the angle of refraction for the wave $90^{\circ}$. This is known as the first critical angle which is calculated $28^{\circ}$ from the Snell's law when the wave moves from PMMA wedge to the steel (Fig. 1). However, the first critical angle is calculated $15^{\circ}$ by using immersion transducers to produce the $L_{C R}$ wave in steel.

The relationship between the velocity of the longitudinal waves which travel parallel to load direction and the strain $(\alpha)$ is expressed by the following equation:

$$
\rho_{0} V_{11}^{2}=\lambda+2 \mu+(2 l+\lambda) \theta+(4 m+4 \lambda+10 \mu) \alpha_{1}
$$

where $\rho_{0}$ is the initial density; $v_{11}$ is the wave velocity of longitudinal wave which propagates parallel to load; $\lambda, \mu$ the second order elastic constants (Lame's constants); I and $m$ are the third order elastic constants; $\vartheta=\alpha_{1}+\alpha_{2}+\alpha_{3}$ which $\alpha_{1}, \alpha_{2}$ and $\alpha_{3}$ are components of the homogeneous triaxial principal strains. For a state of uniaxial stress, $\alpha_{1}=\varepsilon, \alpha_{2}=\alpha_{3}=-v \times \varepsilon$, where $\varepsilon$ is the strain in the direction 1 and $v$ is the Poisson's ratio. Using these values, Equation (1) becomes:

$$
\rho_{0} V_{11}^{2}=\lambda+2 \mu+\left[4(\lambda+2 \mu)+2(\mu+2 m)+v \mu\left(1+\frac{2 \lambda}{\mu}\right)\right] . \varepsilon
$$

The variation of the velocity with the strain is called as "relative sensitivity" and can be calculated by Equation (3).

$$
\frac{d V_{11} / V_{11}}{d \varepsilon}=2+\frac{(\mu+2 m)+v \mu(1+2 l / \lambda)}{\lambda+2 \mu}=L_{11}
$$


, where $L_{11}$ is the dimensionless acoustoelastic constant for $L_{C R}$ waves which should be measured by the uniaxial tensile test.

Equation (3) is rearranged to calculate the stress variation in terms of time-of-flight $\left(d t / t_{0}\right)$, as shown in the Equation (4).

$$
d \sigma=\frac{E\left(d V_{11} / V_{11}\right)}{L_{11}}=\frac{E}{L_{11}}\left(d t / t_{0}\right)
$$

, where $d \sigma$ is the stress variation, $E$ is the elasticity modulus and $t_{0}$ is the time for the wave which travels through a stress free path in the material being investigated. For a fixed probe distance, the travel time of the $L_{C R}$ wave decreases in compressive stress and increases in tensile stress field. The acoustoelastic constant $\left(L_{11}\right)$ links the stress and the velocity or travel time change.

\subsection{Finite Element Welding Simulation}

The problem is formulated as a successively coupled thermal stress analysis. First, a non-linear thermal analysis is performed to calculate the temperature history of the entire domain. Then, the results of the thermal analysis are applied as a thermal body load in a non-linear mechanical analysis determining residual stress and deformations. The finite element (FE) models for both thermal and structural analysis are the same. The general-purposed FE program ANSYS is used for the analyses. A full NewtonRaphson iterative solution technique with direct sparse matrix solver is employed for obtaining a solution. During the thermal analysis, the temperature and the temperature dependent material properties alter very rapidly. Thus, the full Newton-

Raphson technique with using modified material properties is believed to give more precise results.

A conventional technique named "Element Birth and Death" [18] is used for modelling of the deposited weld. A complete FE model is generated in the start of the analysis. However, all elements representing the deposited weld except elements for the tack welds are deactivated by assigning them a very low stiffness. During the thermal analysis, all the nodes of deactivated elements (excluding those shared with the base metal) are also fixed at room temperature till the birth of the respective elements. Deactivated elements are reactivated sequentially when they come under the effect of the welding torch. Linear elements are preferred than higher-order elements in non-linear problems of this type [19]. Here, eight-noded-brick elements with linear shape functions are used in the FE modeling. The basic FE models of plate and pipe are shown in Fig. 2 and Fig. 3.

Material modelling has always been a serious issue in the simulation of welding because of the scarcity of material data at elevated temperatures. Some simplifications and approximations are typically introduced to cope with this problem. These simplifications are necessary because of both lack of data and numerical problems when trying to model the actual hightemperature behaviour of the material [20]. The material properties for stainless steel (TP 304) and A106 carbon steel are taken from Lindgren [21] and P. Chang [22] respectively. The filler metals are determined with help to Schaeffler Diagram [23].

\section{Experimental Procedures}

\subsection{Sample Description}

Two $220 \mathrm{~mm}$ length pipes from stainless steel (TP304) and carbon steel (A106) are welded where their thickness and diameter is $8 \mathrm{~mm}$ and $220 \mathrm{~mm}$ respectively. The root pass is welded by gas tungsten arc welding (GTAW) process while shielded metal arc welding (SMAW) is used to accomplish the other passes according to the Table 1 . The geometry of joint is V-groove $\left(90^{\circ}\right.$ included angle) with $4 \mathrm{~mm}$ gap. Two dissimilar welded plates with the same material, thickness and welding specification of the pipes are also prepared. The dimension of welded plate is $450 \times 400 \times 8 \mathrm{~mm}$ while the weld length is equal to $450 \mathrm{~mm}$.

\subsection{Measurement Device}

The contact measurement device, shown in Fig. 4, includes an ultrasonic box, computer and time of flight (TOF) measuring element. Also, a measuring table is needed to move TOF measuring element accurately and with enough stability. The ultrasonic box is a $100 \mathrm{MHz}$ ultrasonic testing device which has synchronization between the pulser signal and the internal clock, which controls the A/D converter. This allows very precise measurements of the time of flight - better than 1 ns. TOF measuring element includes three normal transducers assembled on an integrated wedge to measure the time of flight. A poly methyl methacrylate (PMMA) material, under the trademark Plexiglas, is cut by laser cutting (with consideration to the results presented by Eltawahni and Olabi [24]) to construct the wedge. A three-probe arrangement is used, with one sender and two 
receivers in order to eliminate environment temperature effect to the travel time. Three normal transducers with the same frequency are used where their nominal frequencies are $2 \mathrm{MHz}$ and the diameter of the piezoelectric elements is $6 \mathrm{~mm}$. A load cell is employed to adjust the pressure on the wedge and keep a uniform film of couplant between the wedge and tested material. The thermocouple and thermometer are used for temperature monitoring to eliminate the temperature effect on the TOF measurement.

Except the TOF measuring element and the holders, the other contact measurement devices for pipe measuring, shown in Fig. 5 , are the same as plate measuring devices. Two types of wedge are needed to measure hoop and axial stress separately. Surface curvature of pipe is considered in laser cutting of bottom surface of the wedges. The transducers are the same as contact measuring devices of the plate. The holders are needed to make enough pressure on the wedge.

The immersion measurement device, shown in Fig. 6, includes an automated 3axis measuring table and TOF measuring element. The ultrasonic box, ultrasonic software and computer are the same as the contact setup. The automated measuring table makes possible to move the TOF measuring element with $1 \mu \mathrm{m}$ resolution and 3D measuring of residual stresses. TOF measuring element includes two $2 \mathrm{MHz}$ immersion transducers assembled on an integrated wedge to measure the time of flight. Because of welding deformations in the surface of the tested material, the gap between transducers and tested surface is changed when the TOF measuring element moves. To eliminate effect of these changes on the measured TOF, an adjusting transducer is used to keep the distance constant. The adjusting transducer is connected to a traditional ultrasonic flaw detector not to interface in TOF measuring process by the main ultrasonic box.

\subsection{Determination of $L_{C R}$ Penetration Depth}

When the $L_{C R}$ technique is applied to an application with limited wall thickness, the depth of the $L_{C R}$ wave penetration is expected to be a function of frequency. Since there is no definite relation for $L_{C R}$ depth and frequency, it should be measured experimentally. A variable depth groove is cut in two $8 \mathrm{~mm}$ thickness stainless and carbon steel plates to produce a barrier preventing the $L_{C R}$ wave from reaching the receiver transducer. These plates are also tested by the contact and immersion ultrasonic devices separately. The penetration depth is measured $2 \mathrm{~mm}$ for $L_{C R}$ wave by $2 \mathrm{MHz}$ contact and immersion transducers in both of stainless and carbon steel plate.

\subsection{Evaluation of the Calibration Constants}

To evaluate the calibration constants (acoustoelastic constant and free stress TOF), the calibration samples are taken from both sides of the dissimilar plates. Three rectangular tension test specimens are extracted to determine acoustoelastic constant $\left(L_{11}\right)$ from stainless steel side, carbon steel side and the weld zone separately. Metallographic analysis of the weld shows that the heat affected zone (HAZ) is not large enough to extract tensile test sample (Fig. 7). Therefore the acoustoelastic constant of the weld is used in stress calculation of the HAZ. To evaluate the residual stress based on the Equation (4), the value $t_{0}$ is measured directly from the stress-free samples. The acoustoelastic constant $\left(L_{11}\right)$ is also deduced experimentally from a uniaxial tensile test related to contact and immersion mode (Fig. 8 and Fig. 9). The stress-free samples are the same as the tensile test specimens which are stress relieved by heat treatment. The tensile test specimens are constructed with the dimensions of Sheet type (1/2 in. wide) according to the ASTM: E8 standard while the width of grip section and reduced section are $20 \mathrm{~mm}$ and $12.5 \mathrm{~mm}$ respectively.

\section{Results and Discussion}

\subsection{Results of Finite Element Analysis}

In this study, the 3D finite element analysis for welding simulation is verified by experimental measurements. The validated finite element model is then used to predict the residual stresses and verify the ultrasonic measurement results.

The verification of the thermal analysis is done by comparison of the real melted zone dimension, shown in Fig. 7, and the $\mathrm{MZ}$ size estimated by FE analysis. The mechanical analysis is also verified by hole-drilling method. Fig. 10 and Fig. 11 show the comparison of finite element results with the hole-drilling measurements in the plate and pipe respectively while a good agreement is observed. The average of FE results in $2 \mathrm{~mm}$ depth from the surface is compared with the hole-drilling method which also gives the average of residual stress measured in the $2 \mathrm{~mm}$ depth hole. The hole-drilling method is performed in three different points (on the plate and pipe) based on the characterizations described in ASTM: E837. 


\subsection{Results of Acoustoelastic Constant Measurement}

The results of tensile test, performed to measure acoustoelastic constant, are shown in Fig. 12 where the slope of the lines represents $L_{11}$ acoustoelastic constants. All the measured data are related to the plate and will be used in Equation (4) to calculate residual stresses of the tested plate and pipe. The results show the contact acoustoelastic constant of the carbon steel (2.377) is higher than stainless steel (2.145) and the weld constant is the maximum (2.578). The immersion acoustoelastic constants are measured equal to $2.123,2.386$ and 2.591 related to the stainless steel, carbon steel and the weld respectively. The comparison between contact and immersion acoustoelastic constant measurement show no considerable difference. It approves that the accoustoelastic constant is an internal property of the material which is not influenced by changing the measurement method.

\subsection{Results of Ultrasonic Stress Measurement}

Using the acoustoelastic constant along with the measured TOF in Equation (4) leads to calculation of ultrasonic residual stresses shown in Fig. 13 and Fig. 14. The ultrasonic results are also compared with the FE analysis while a good agreement is achieved. It means that combination of finite element welding simulation with ultrasonic stress measurement using $L_{C R}$ waves (this combination is called as $F E L_{C R}$ by Javadi et al [25]) can properly evaluate welding residual stresses of dissimilar joints.

The wave speed for $L_{C R}$ waves is affected by the average stress in a layer which may be a few millimetres thick [14]. The both contact and immersion ultrasonic methods measure the average of stresses in a determined depth. It means that in the case of $2 \mathrm{MHz} L_{C R}$ wave, which travels within $2 \mathrm{~mm}$ layer of the surface, average of residual stress in this zone is ultrasonically measurable. Hence, in the FE method, the average of residual stresses for all the nodes located in the range of 0-2 mm under the surface are calculated to compare with those obtained from ultrasonic measurements. Furthermore, this confirms the potential of the $L_{C R}$ waves to penetrate in the depth of stainless and carbon steels which have also been reported by some of previous studies $[9,13-14,26-30]$.

The distribution of residual stress is not symmetric and the peak of residual stress is occurred in the stainless steel side in the both of the plate and pipe. It is justified by higher yield stress of stainless steel (265 MPa) in comparison with the carbon steel side (240 MPa). The difference between welding residual stress of two dissimilar materials, is also confirmed by the majority of previous studies related to the dissimilar welding $[1,7,8]$.

\subsection{Disagreement between FE analysis and UItrasonic Measurements}

The disagreement between ultrasonic and FE results, listed in Table 2, is changed according to the measured zone while the maximum is occurred in the HAZ and the parent material (PM) shows the best agreement. Since the dimension of HAZ is not large enough to extract the tensile test sample, the acoustoelastic constant of the weld zone is used to calculate residual stresses of the HAZ. However, using the acoustoelastic constant of weld zone as the HAZ acoustoelastic constant leads to relatively high measurement error [30].

The disagreement between FE and ultrasonic results of the weld zone reaches to $40 \mathrm{MPa}$ in axial stress measurements of the pipe. The high disagreement can be probably because of acoustoelastic constant which is only measured on the plate. It has been tried to produce the same welding specifications in the pipe and plate but difference between straight and circumferential welding processes is inevitable. However, the $40 \mathrm{MPa}$ is an acceptable error in comparison with the other methods for nondestructive stress measurement. The disagreement results in the parent material zone do not exceed than $\pm 25 \mathrm{MPa}$ which is about $\% 10$ of yield strength of the tested materials.

\subsection{Comparison between Contact and Immersion Measurement Results}

The results show that the immersion measurements are in better agreement with FE results in both of the dissimilar pipe and plate. Using the ultrasonic couplant between wedge and tested surface is eliminated in the immersion measurement which leads to more accurate results. Employing the automated 3axis measuring table with $1 \mu \mathrm{m}$ resolution is another reason of smoother residual stress distribution of immersion in comparison with the contact method.

The immersion measurements of the plate are more time-consuming than the contact method because of setting the adjusting transducer in all of the points measured by the immersion technique. Unlike the plate, immersion inspection of the pipe takes less time than contact measurement. The reason is practical limitation in holding system of the TOF measuring element during the contact measurement of the pipe. It is needed to unscrew the holder after finishing the TOF measurement of a point and 
hold it again in the new tested point. This time-consuming process should be repeated for more than 100 tested points of the pipe while the TOF measurement is also repeated 3 times per tested points to decrease measuring error.

Using the second receiver is not necessary in the immersion measurements because the environmental effects are more controllable in comparison with the contact inspection. Using the load cell, temperature monitoring system and second receiver is recommended in the contact measurement setup to eliminate environmental effects. Although these devices are not mandatory in the immersion measurement but using adjusting transducer and automated measuring table raise the cost of experimental setup. Hence, the price of immersion experimental devices is approximately same as the contact setup. The measurement of immersion acoustoelastic constant is also more difficult than contact constant measurement because of sealing difficulties during the tensile test.

Despite the above considerations, there is no significant difference between using the contact and immersion $L_{C R}$ waves in the ultrasonic stress measurements of the dissimilar joints. Both of them can measure the residual stress with an acceptable accuracy. Selecting between them depend on geometry and dimensions of tested structure and also the available experimental devices.

\subsection{Practical Difficulties of Ultrasonic Stress Measurement in Dissimilar Welded Joints}

There are also some practical difficulties in ultrasonic stress measurements of the dissimilar joints. The ultrasonic wave velocity is different in two sides of the weld which leads to difference in calculation of the first critical angle. It is needed to construct two wedges with different angle to move from one side to another side of dissimilar joint. Construction of two wedges with exactly the same dimensions is impractical while a little difference can be an important reason of ultrasonic measurement error. Furthermore, the penetration depth of $L_{C R}$ wave is affected by the material properties and can be differed in dissimilar materials. Since the residual stresses are altered through the thickness, it is not possible to achieve a continuous distribution of residual stress when the penetration depth is not constant during the ultrasonic inspection. However, these limitations are not observed in the case of investigated stainless to carbon steel joint because the velocity of ultrasonic wave is measured approximately the same which do not considerably influence on the first critical angle. The penetration depth of the $L_{C R}$ wave is also the same for the investigated materials. Therefore, the same wedge is employed in ultrasonic measurement of both sides of the dissimilar joint. Therefore, it is not recommended using the ultrasonic stress measurement in dissimilar joint of materials which their ultrasonic properties are strongly different.

Furthermore, different acoustic properties of dissimilar metals can produce a complicated weld region in terms of ultrasonic measurement which cause unsatisfying results of stress evaluation in this zone. However, decreasing in dimension of the weld zone could lead to smaller contact area of the ultrasonic wedge with complex acoustic properties of the weld. Since using laser welding could produce a small welding pool and a narrow HAZ [2], the ultrasonic method would be better option for stress measurement of dissimilar joints produced by laser welding in comparison with the arc welding process.

\section{Conclusion}

The main goal of this study is comparison between contact and immersion ultrasonic measurements of welding residual stress in dissimilar joints. A combination of finite element welding simulation and $L_{C R}$ ultrasonic waves is employed to reach this goal. According to achieved results, it can be concluded that:

1) The ultrasonic measurements of dissimilar joints show an acceptable agreement with finite element analysis. The best agreement is observed in the parent material while the maximum difference is measured in the HAZ.

2) The immersion ultrasonic measurements show better agreement with FE results in comparison with the contact method. 
3) The contact measurement is more time-consuming than immersion inspection in case of the dissimilar welded pipes while the situation is reversed about the dissimilar welded plates.

4) Using some of cost-consuming equipments (like load cell, temperature monitoring system and second receiver probe) are not necessary in the immersion measurements because the environmental effects are more controllable in comparison with the contact inspection.

5) It is not recommended using the ultrasonic stress measurement in dissimilar joint of materials which their ultrasonic properties are strongly different.

6) There is no significant difference between using the contact and immersion $L_{C R}$ waves in the ultrasonic stress measurements of dissimilar joints. Both of them could measure the residual stress with an acceptable accuracy. Selecting between them depends on geometry and dimensions of tested structure and also the available experimental devices.

\section{References}

[1] Anawa EM, Olabi AG. Using Taguchi method to optimize welding pool of dissimilar laser-welded components. Optics \& Laser Technology 2008; 40: 379-88.

[2] Olabi AG, Hashmi MSJ. The effect of post-weld heat-treatment on mechanical-properties and residual-stresses mapping in welded structural steel. Journal of Materials Processing Technology 1995; 55: 117-22.

[3] Olabi AG, Hashmi MSJ. The Microstructure and Mechanical Properties of Low Carbon Steel Welded Components After the Application of PWHTs. Journal of Materials Processing Technology 1996; 56:88-97.

[4] Olabi AG, Hashmi MSJ. Stress Relief Procedures for Low Carbon Steel (1020) Welded Components. Journal of Materials Processing Technology 1996; 56:552-62.

[5] Olabi AG, Hashmi MSJ. Effects of the stress-relief conditions on a martensite stainless-steel welded component. Journal of Materials Processing Technology 1998; 77: 216-25.

[6] Olabi AG, Casalino G, Benyounis KY, Rotondo A. Minimisation of the residual stress in the heat affected zone by means of numerical methods. Materials and Design 2007; 28: 2295-302.

[7] Anawa EM, Olabi AG. Control of welding residual stress for dissimilar laser welded materials. Journal of Materials Processing Technology 2008; 204:22-33.

[8] Anawa EM, Olabi AG. Effect of laser welding conditions on toughness of dissimilar welded components. J Appl Mech Mater 2006; 5-6: 375-80.

[9] Rossini NS, Dassisti M, Benyounis KY, Olabi AG. Methods of measuring residual stresses in components. J Materials \& Design 2012; 35:572-88.

[10] Egle DM, Bray DE. Measurement of Acoustoelastic and Third-Order Elastic Constants for Rail Steel. J Acoust Soc Am 1976; 60: 741-44.

[11] Leon-Salamanca T, Bray DF. Residual Stress Measurements in Steel Plates and Welds Using Critically Refracted $\left(\mathrm{L}_{\mathrm{CR}}\right)$ Waves. Research in Nondestructive Evaluation 1995; 7: 169-84.

[12] Tanala E, Bourse G, Fremiot M, De Belleval JF. Determination of near surface residual stresses on welded joints using ultrasonic method. NDT\&E International 1995; 28: 83-8.

[13] Belahcene F, Lu J. Determination of residual stress using critically refracted longitudinal waves and immersion mode. J Strain Analysis 2002; 37: 13-9.

[14] Palanichamy P, Vasudevan M, Jayakumar T. Measurement of residual stresses in austenitic stainless steel weld joints using ultrasonic technique. Science and Technology of Welding and Joining 2009; 14: 166-71.

[15] Goldak J, Bibby M. Computational Thermal Analysis of Welds. Modeling of Casting and Welding Processes 1988; 4: $153-66$. 
[16] Yan D, Wu A, Silvanus J, Shi Q. Predicting residual distortion of aluminum alloy stiffened sheet after friction stir welding by numerical simulation. J Materials \& Design 2011; 32: 2284-91.

[17] Sattari-Far I, Javadi Y. Influence of welding sequence on welding distortions in pipes. Int J of Pressure Vessels and Piping 2008; 85: 265-74.

[18] Lindgren LE. Finite Element Modelling and Simulation of Welding Part 1 Increased complexity. J Thermal Stress 2001; 24: 141-92.

[19] Deng D, Murakawa H. Numerical simulation of temperature field and residual stress in multi-pass welds in stainless steel pipe and comparison with experimental measurements. Computational Materials Science 2006; 37: 269-77.

[20] Lindgren LE. Finite element modelling and simulation of welding part 2: improved material modelling. J Thermal Stress 2001; 24: 195-231.

[21] Lindgren LE, Hedblom R. Modelling of addition of filler material in large deformation analysis of multipass welding. Commun Numer Methods Eng 2001; 17: 647-57.

[22] Chang P, Teng T. Numerical and experimental investigations on the residual stresses of the butt-welded joints. Computational Materials Science 2004; 29: 511-22.

[23] Schaeffler A. Constitution diagram for stainless steel weld metal. Metal Progress 1949; 56: 680-B.

[24] Eltawahni HA, Olabi AG, Benyounis KY. Effect of process parameters and optimization of CO2 laser cutting of ultra high-performance polyethylene. Materials and Design 2010; 31: 4029-38.

[25] Javadi Y, Akhlaghi M, Ahmadi Najafabadi M. Using Finite Element and Ultrasonic Method to Evaluate Welding Longitudinal Residual Stress through the Thickness in Austenitic Stainless Steel Plates. J Materials \& Design 2013; 45: $628-42$.

[26] Bray DE, Tang W. Subsurface Stress Evaluation in Steel Plates and Bars with the LCR Ultrasonic Wave. Nuclear Engineering and Design 2001; 207: 231-40.

[27] Bray DE. Ultrasonic Stress Measurement in Pressure Vessels, Piping and Welds. Journal of Pressure Vessel Technology 2002; 124: 326-35.

[28] Lu H, Liu XS, Yang JG, Zhang SP, Fang HY. Ultrasonic stress evaluation on welded plates with Lcr wave. Science and Technology of Welding and Joining 2008; 13: 70-4.

[29] Gachia S, Belahcene F, Boubenider F. Residual stresses in AA7108 aluminium alloy sheets joined by friction stir welding. Nondestructive Testing and Evaluation 2009; 24: 301-9.

[30] Qozam H, Chaki S, Bourse G, Robin C, Walaszek H, Bouteille P. Microstructure Effect on the Lcr Elastic Wave for Welding Residual Stress Measurement. Experimental Mechanics 2010; 50: 179-85. 


\section{List of Table Captions}

Table 1: Welding specifications of Dissimilar Joint

Table 2: The maximum disagreement between FE with the contact and immersion ultrasonic results of dissimilar plate and pipe 


\section{List of Figure Captions}

Figure 1. $L_{C R}$ wave propagated in the a) steel plate and b) steel pipe through the PMMA wedge

Figure 2. Basic FE model of Dissimilar Plate

Figure 3. Basic FE model of Dissimilar Pipe

Figure 4. Contact Measurement Devices (Plate)

Figure 5. Contact Measurement Devices (Pipe)

Figure 6. Immersion Measurement Devices (Plate and Pipe)

Figure 7. Overetched section to make the HAZ visible

Figure 8. Tensile test to evaluate contact acoustoelastic constant

Figure 9. Tensile test to evaluate immersion acoustoelastic constant

Figure 10. Comparison of Hole-drilling method with the FE Results in the Dissimilar Welded Plate

Figure 11. Comparison of Hole-drilling method with the FE Results according to the a) Axial Residual Stress and b) Hoop Residual Stress in the Dissimilar Welded Pipe

Figure 12. Result of Tensile test to evaluate a) contact and b) immersion acoustoelastic constant

Figure 13. Longitudinal Residual Stress Comparison of FE with Contact and Immersion Ultrasonic Measurement in a) Entire of the Plate and b) HAZ and Weld Zone (Dissimilar Welded Plate)

Figure 14. Comparison of FE with Contact and Immersion Ultrasonic Measurement according to the a) Axial Residual Stress and b) Hoop Residual Stress (Dissimilar Welded Pipe) 


\section{Tables}

Table 1: Welding specifications of Dissimilar Joint

\begin{tabular}{cccccc}
\hline Pass No. & $\begin{array}{c}\text { Welding } \\
\text { Method }\end{array}$ & $\begin{array}{c}\text { Welding } \\
\text { Voltage }(\mathrm{V})\end{array}$ & $\begin{array}{c}\text { Welding Current } \\
(\mathrm{A})\end{array}$ & $\begin{array}{c}\text { Welding Speed } \\
(\mathrm{cm} / \mathrm{min})\end{array}$ & Filler Material \\
\hline 1 (root pass) & GTAW & 9 & 95 & 3.5 & ER308L \\
2 & SMAW & 27 & 115 & 22 & E 308L-16 \\
3 & SMAW & 27 & 145 & E 308L-16 \\
\hline
\end{tabular}

Table 2. The maximum disagreement between FE with the contact and immersion ultrasonic results of dissimilar plate and pipe

\begin{tabular}{|c|c|c|c|c|}
\hline & & $\begin{array}{l}\text { Parent } \\
\text { Material }\end{array}$ & HAZ & Weld \\
\hline \multirow{2}{*}{$\begin{array}{l}\text { Maximum disagreement between } \\
\text { Ultrasonic with FE results in the Dissimilar } \\
\text { Plate }\end{array}$} & $\begin{array}{l}\text { Contact } \\
\text { Ultrasonic }\end{array}$ & $20.89 \mathrm{MPa}$ & $\begin{array}{l}59.29 \\
\mathrm{MPa}\end{array}$ & $33.82 \mathrm{MPa}$ \\
\hline & $\begin{array}{l}\text { Immersion } \\
\text { Ultrasonic }\end{array}$ & $15.12 \mathrm{MPa}$ & $\begin{array}{l}50.53 \\
\mathrm{MPa}\end{array}$ & $27.82 \mathrm{MPa}$ \\
\hline \multirow{2}{*}{$\begin{array}{l}\text { Maximum disagreement between Contact } \\
\text { Ultrasonic with FE results related to the } \\
\text { Axial Residual Stress of the Dissimilar Pipe }\end{array}$} & $\begin{array}{l}\text { Contact } \\
\text { Ultrasonic }\end{array}$ & $24.37 \mathrm{MPa}$ & $\begin{array}{l}58.68 \\
\mathrm{MPa}\end{array}$ & $39.95 \mathrm{MPa}$ \\
\hline & $\begin{array}{l}\text { Immersion } \\
\text { Ultrasonic }\end{array}$ & $16.8 \mathrm{MPa}$ & $\begin{array}{l}48.68 \\
\mathrm{MPa}\end{array}$ & $29.68 \mathrm{MPa}$ \\
\hline \multirow{2}{*}{$\begin{array}{l}\text { Maximum disagreement between } \\
\text { Ultrasonic with FE results related to the } \\
\text { Hoop Residual Stress of the Dissimilar Pipe }\end{array}$} & $\begin{array}{l}\text { Contact } \\
\text { Ultrasonic }\end{array}$ & $21.43 \mathrm{MPa}$ & $\begin{array}{l}39.47 \\
\mathrm{MPa}\end{array}$ & $29.87 \mathrm{MPa}$ \\
\hline & $\begin{array}{l}\text { Immersion } \\
\text { Ultrasonic }\end{array}$ & 17.9 MPa & $\begin{array}{l}32.14 \\
\mathrm{MPa}\end{array}$ & 19.73 $\mathrm{MPa}$ \\
\hline
\end{tabular}


10. Figures

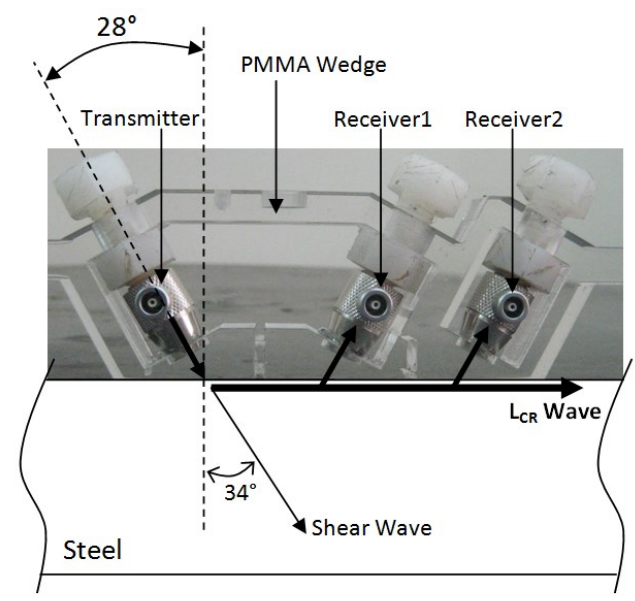

(a)

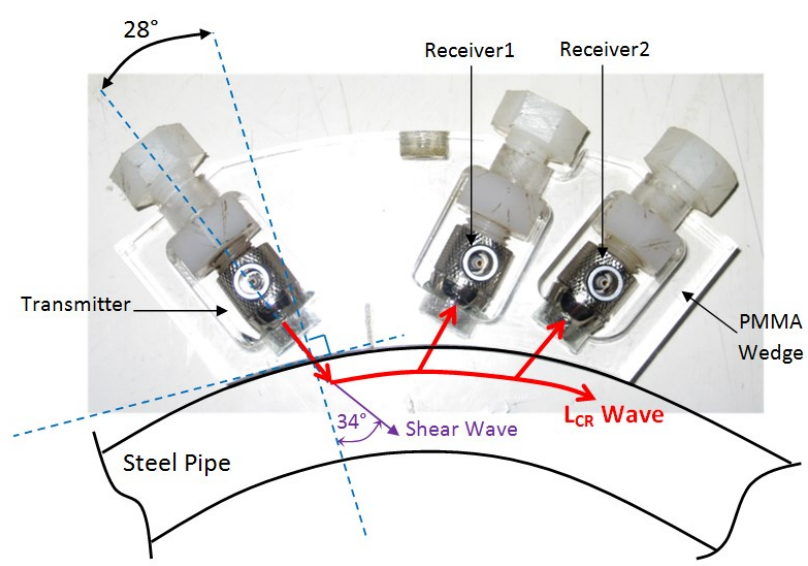

(b)

Figure 1.LCR wave propagated in the a) steel plate and b) steel pipe through the PMMA wedge

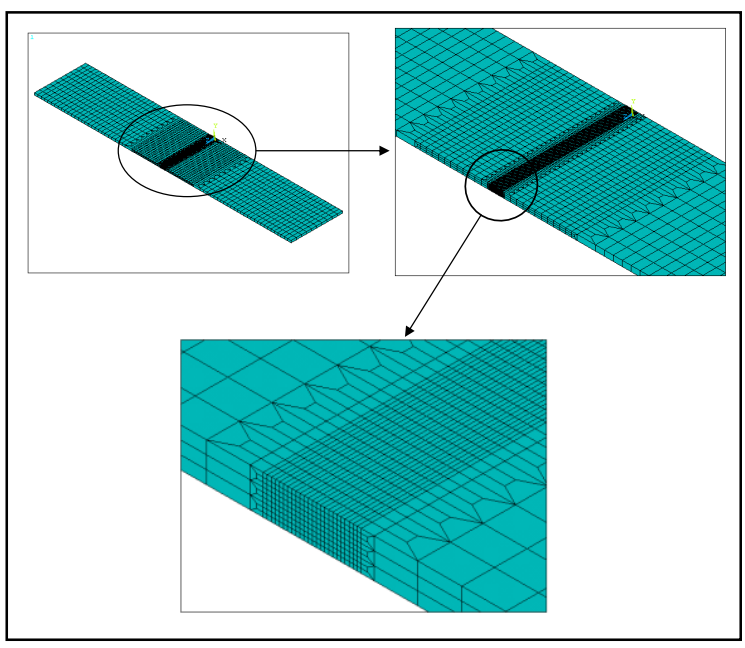

Figure 2. Basic FE model of Dissimilar Plate 


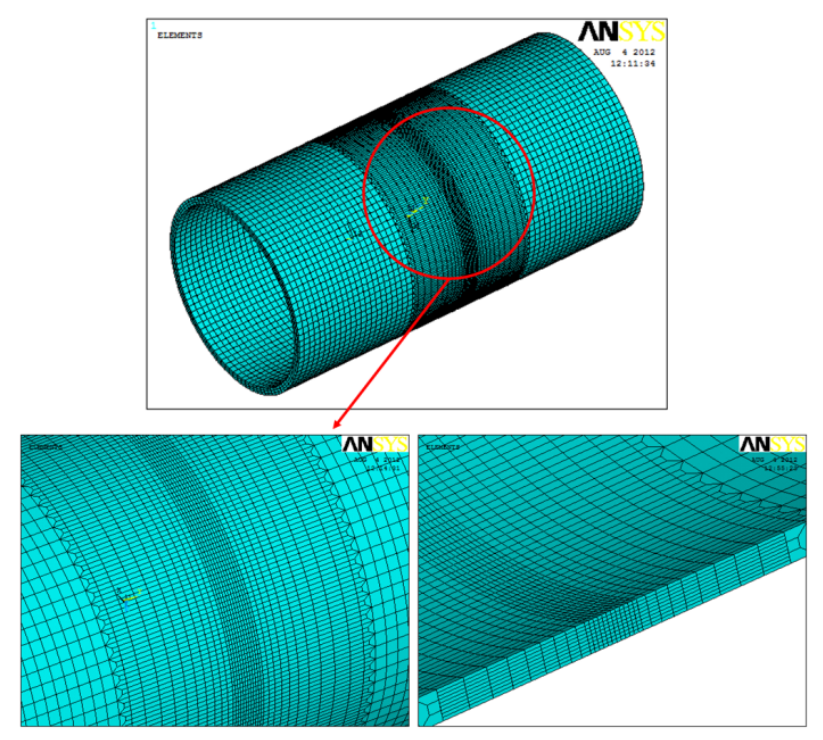

Figure 3. Basic FE model of Dissimilar Pipe
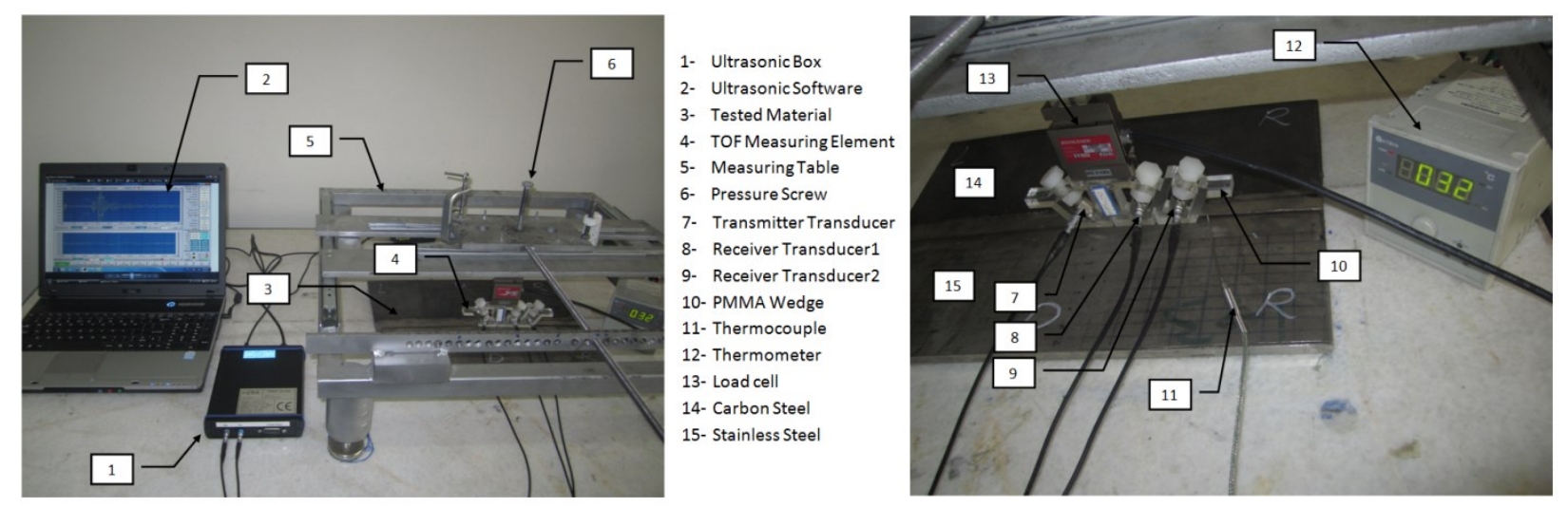

Figure 4. Contact Measurement Devices (Plate)

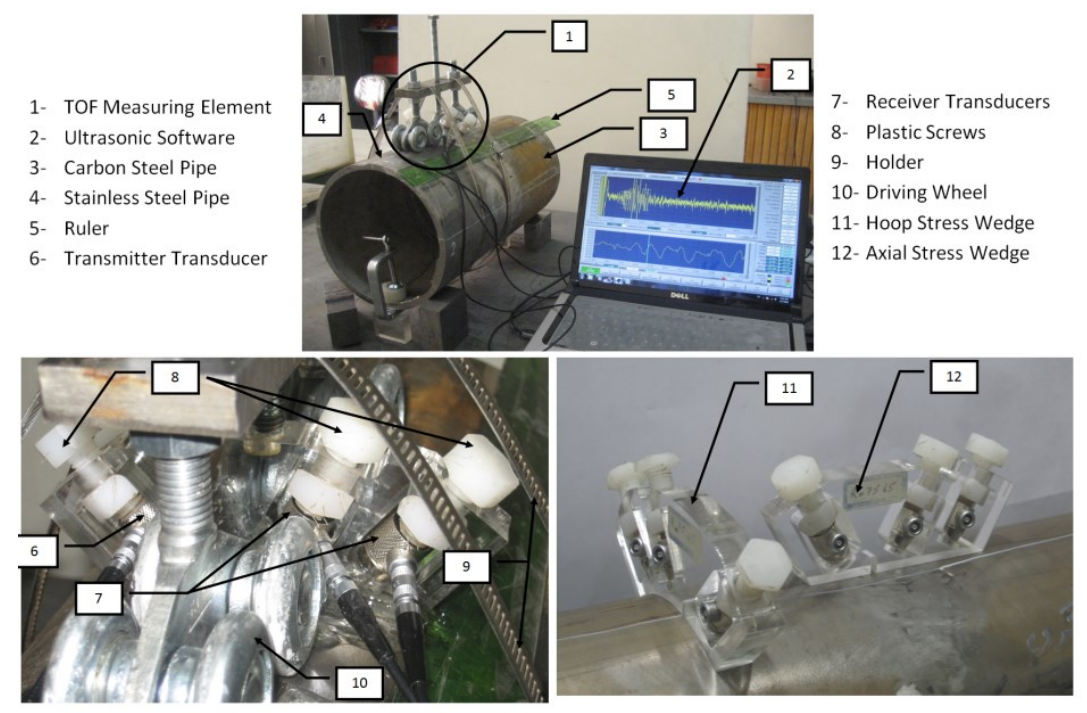


Figure 5. Contact Measurement Devices (Pipe)
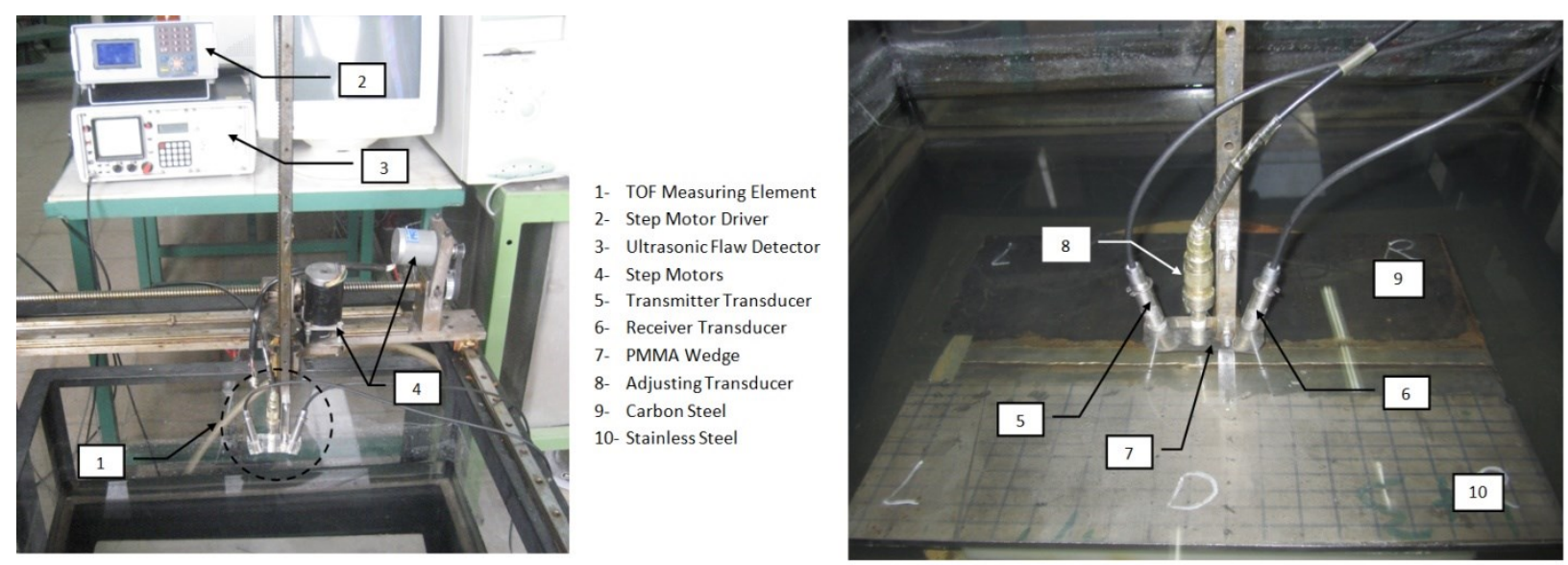

Figure 6. Immersion Measurement Devices (Plate and Pipe)

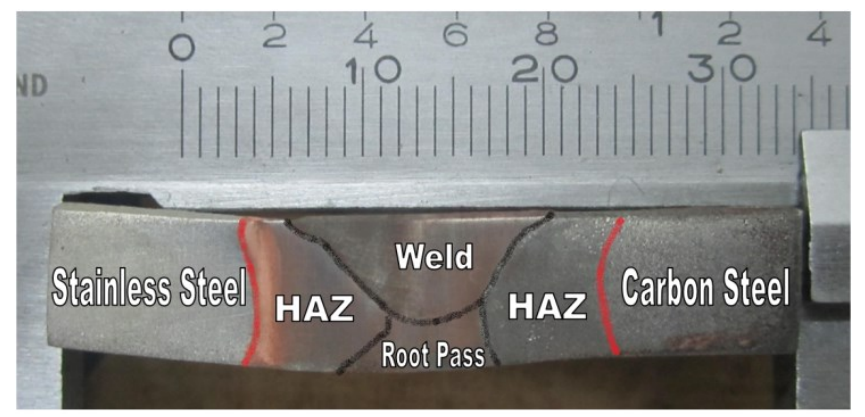

Figure 7. Overetched section to make the HAZ visible
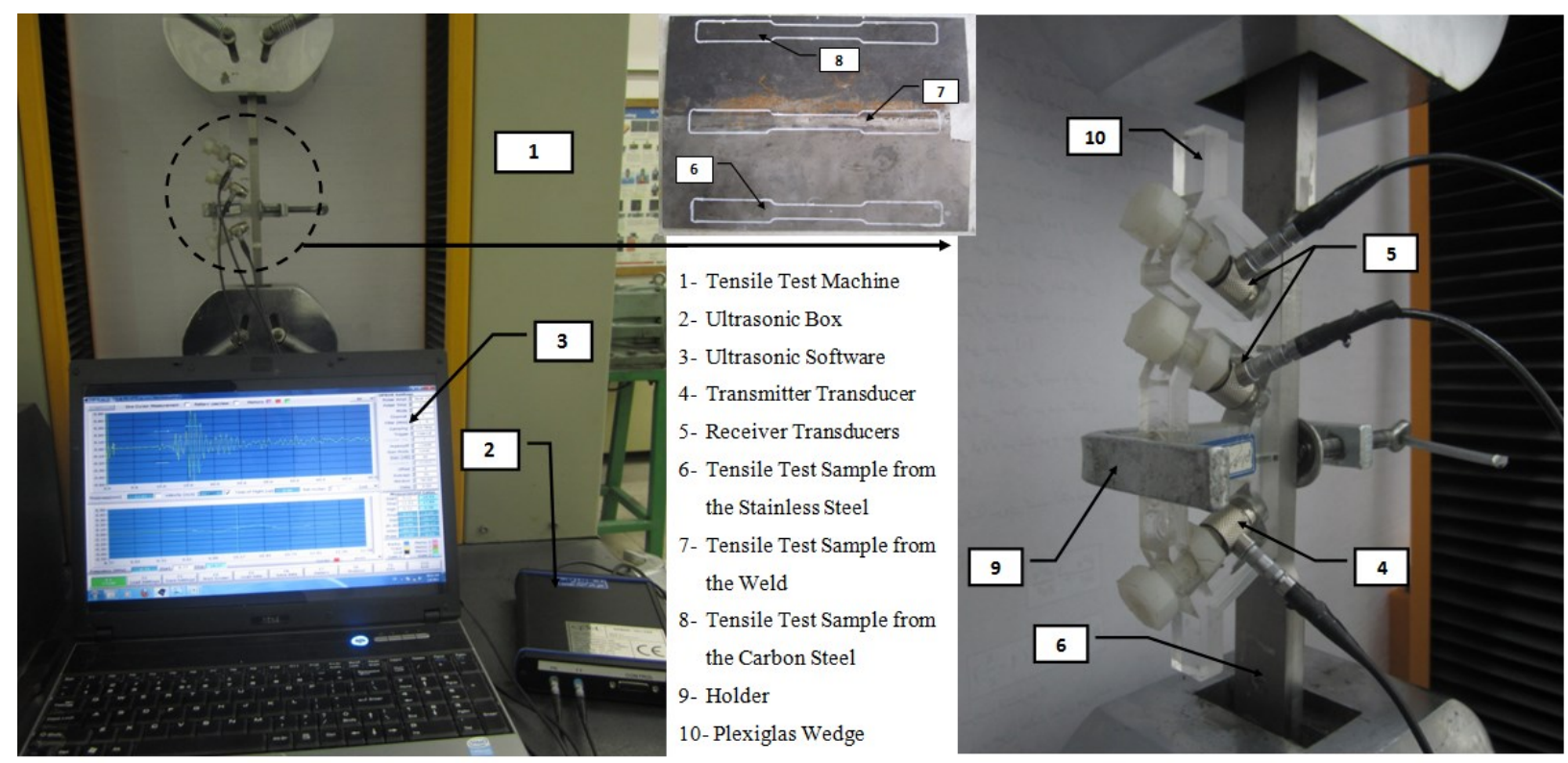

Figure 8. Tensile test to evaluate contact acoustoelastic constant 


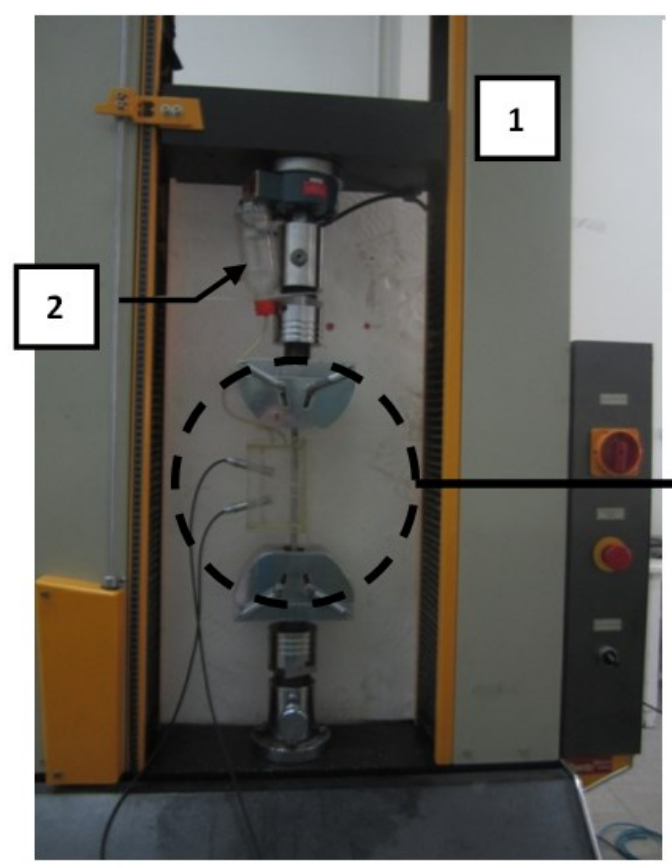

1) Tensile Test Machine

2) Bottle of Water

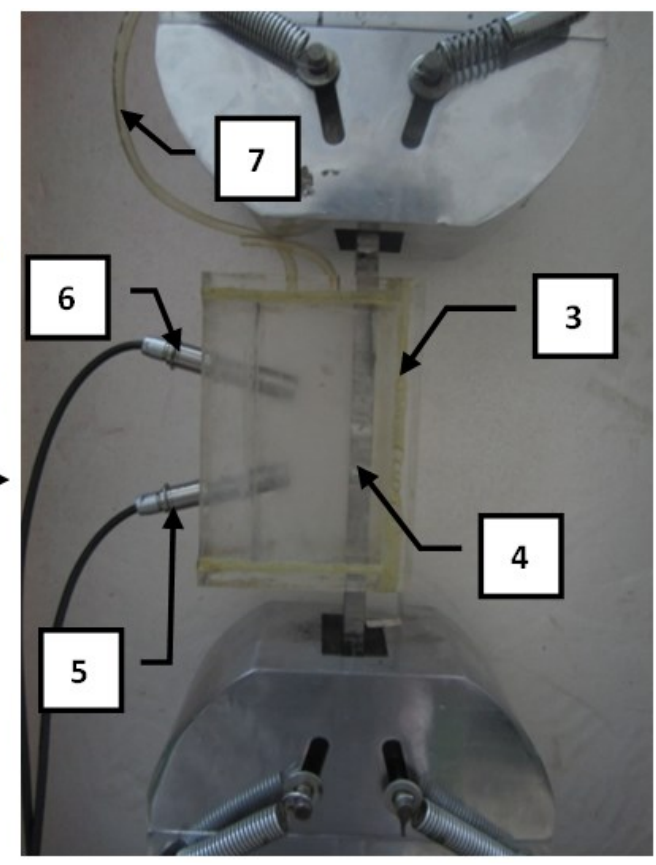

Figure 9. Tensile test to evaluate immersion acoustoelastic constant

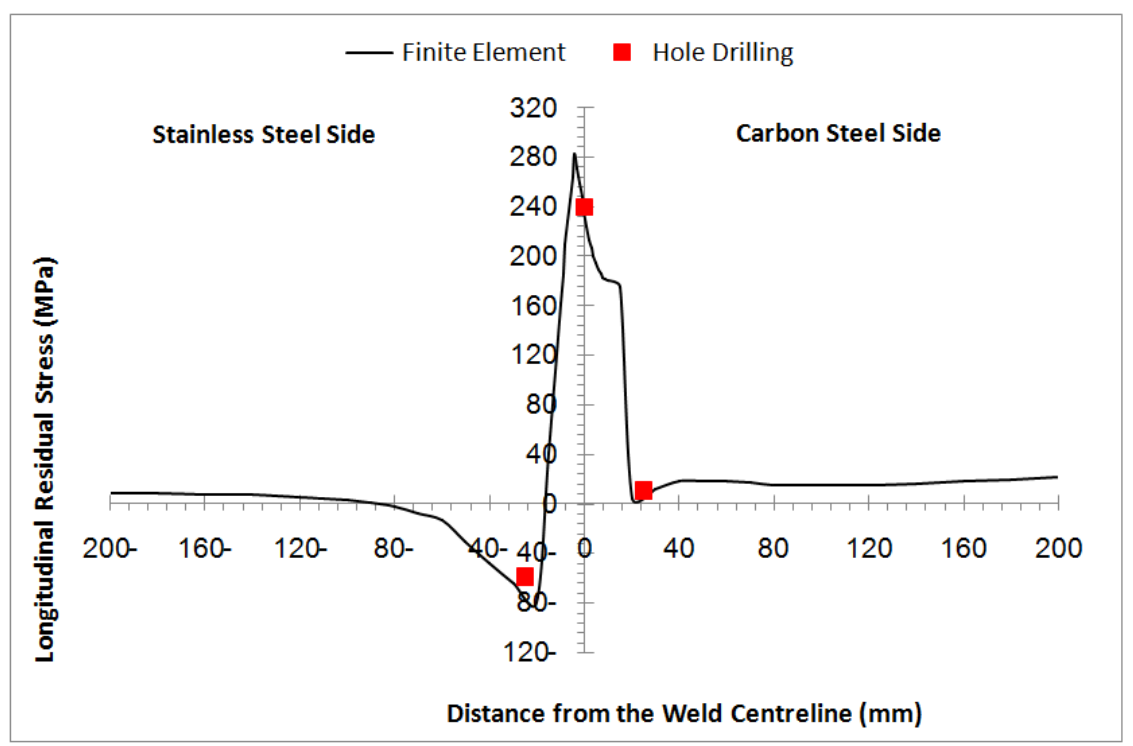

Figure 10. Comparison of Hole-drilling method with the FE Results in the Dissimilar Welded Plate 


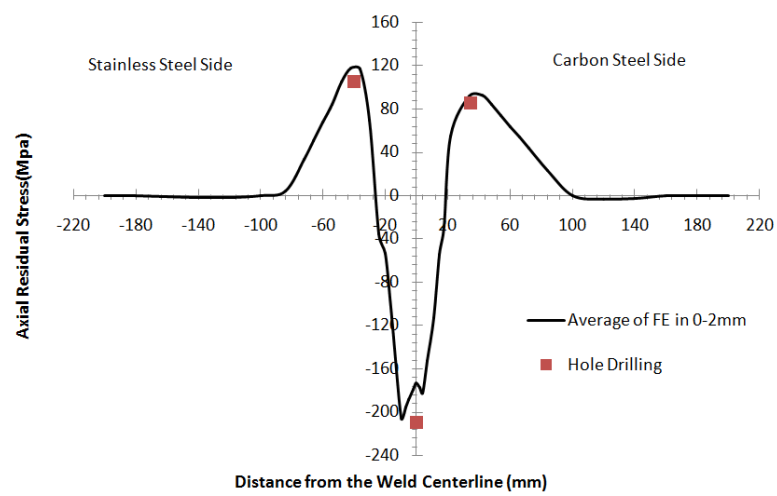

(a)

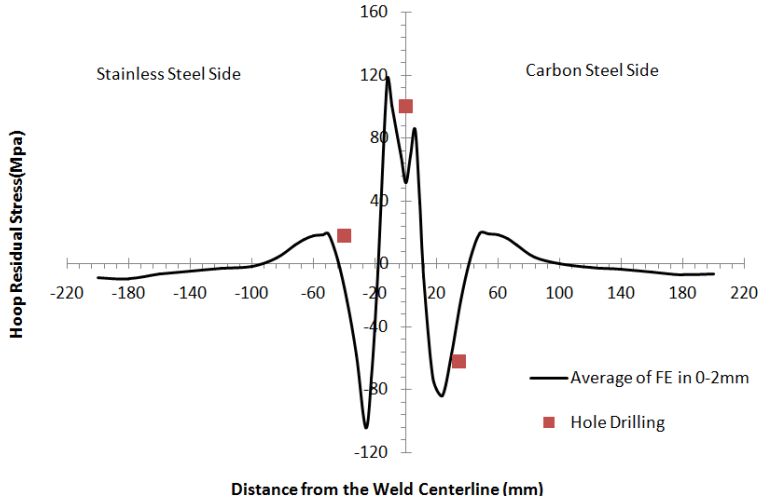

(b)

Figure 11. Comparison of Hole-drilling method with the FE Results according to the a) Axial Residual Stress and b) Hoop Residual Stress in the Dissimilar Welded Pipe

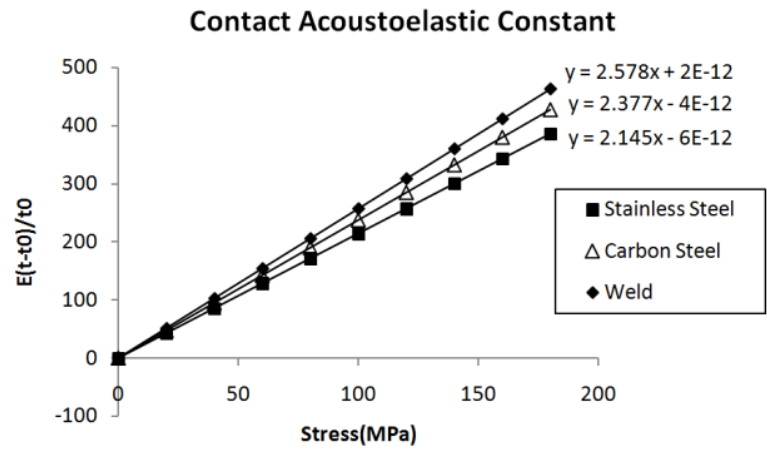

(a)

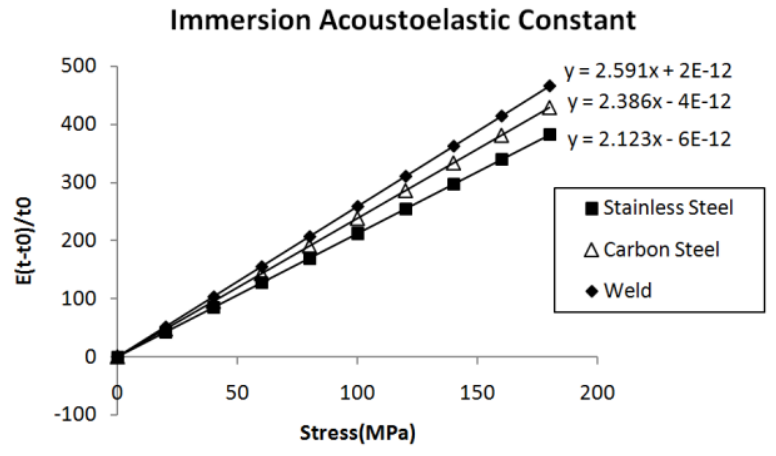

(b)

Figure 12. Result of Tensile test to evaluate a) contact and b) immersion acoustoelastic constant

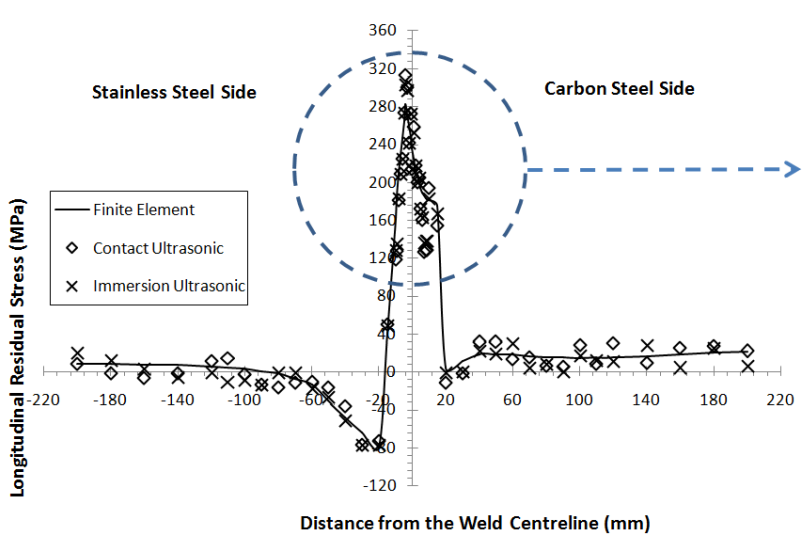

(a)

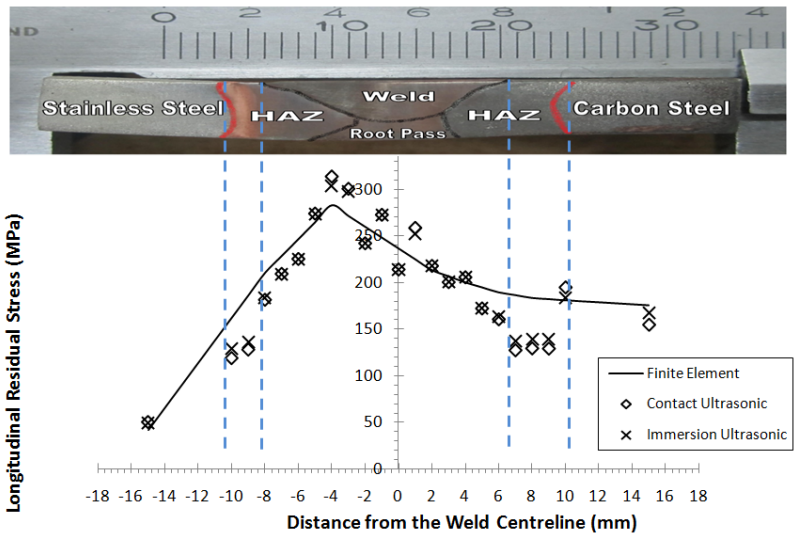

(b)

Figure 13. Longitudinal Residual Stress Comparison of FE with Contact and Immersion Ultrasonic Measurement in a) Entire of the Plate and b) HAZ and Weld Zone (Dissimilar Welded Plate) 


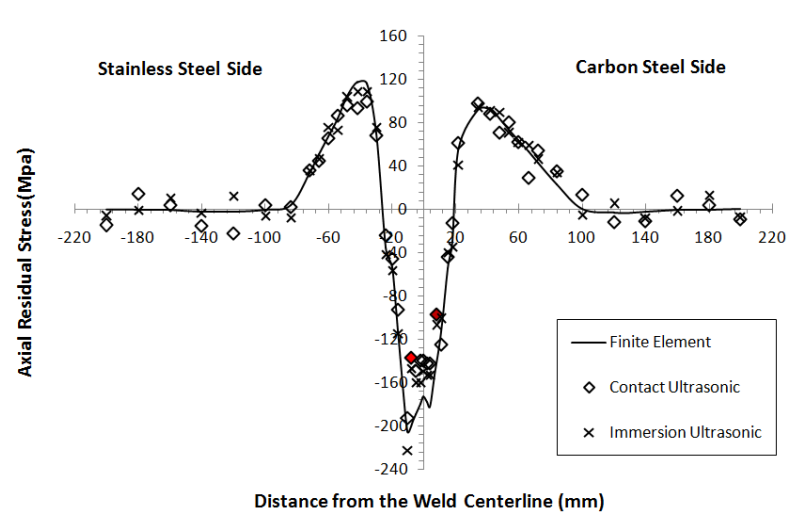

(a)

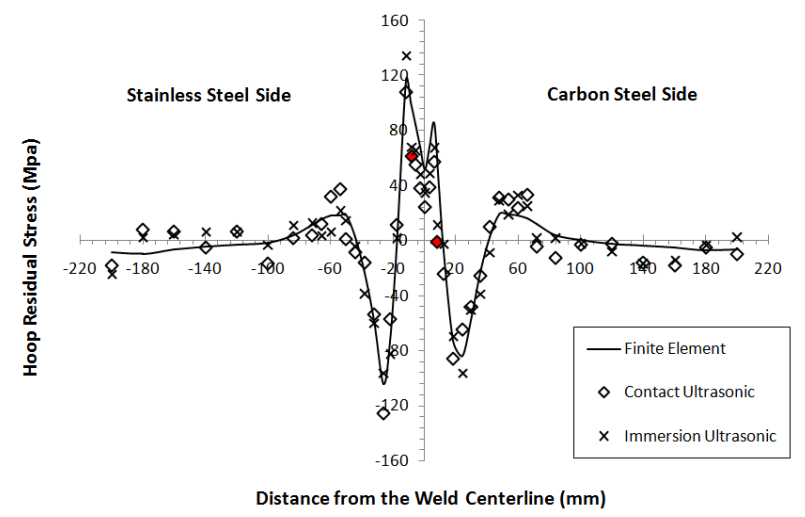

(b)

Figure 14. Comparison of FE with Contact and Immersion Ultrasonic Measurement according to the a) Axial Residual Stress and b) Hoop Residual Stress (Dissimilar Welded Pipe) 